\title{
Community-based screening of Chagas disease among Latin American migrants in a non-endemic country: an observational study
}

Violeta Ramos-Sesma ${ }^{1 \dagger}$, Miriam Navarro ${ }^{2,3 \dagger}$, Jara Llenas-García ${ }^{4,5}$, Concepción Gil-Anguita ${ }^{6}$, Diego Torrus-Tendero 7,8, Philip Wikman-Jorgensen ${ }^{9}$, María García-López ${ }^{4}$, Concepción Amador-Prous 6 , María-Paz Ventero-Martín ${ }^{10}$, Pedro Guevara-Hernández ${ }^{4}$, Ana Garijo-Saiz ${ }^{6}$, Ares Sanchez-Sanchez ${ }^{11}$, Cristina Bernal-Alcaraz ${ }^{4}$, Ana-Isabel Pujades-Tarraga ${ }^{6}$, Roser Muñoz-Perez ${ }^{12}$, María Flores-Chávez ${ }^{13}$ and José-Manuel Ramos-Rincón $n^{5,7^{*}}$ (D) on behalf of the \#CorazonesSinChagas Platform

\begin{abstract}
Background: Chagas disease is a parasitic disease endemic to Latin America, but it has become a disease of global concern due to migration flows. Asymptomatic carriers may host the parasite for years, without knowing they are infected. The aim of this study is to assess prevalence of Chagas disease and evaluate the participants' level of knowledge between Latin American migrants attending a community-based screening campaign.
\end{abstract}

Methods: Three community-based campaigns were performed in Alicante (Spain) in 2016, 2017 and 2018, including educational chats and blood tests for Trypanosoma cruzi serology. Participants completed a questionnaire assessing knowledge about the mechanisms of transmission, disease presentation, diagnosis, and treatment. People seropositive for T. cruzi underwent diagnostic confirmation by two different tests. Results were analyzed by multivariable logistic regression and expressed as adjusted odds ratios (aORs), adjusting for age, sex, and time in Spain.

Results: A total of 596 participants were included in the study; $17 \%$ were aged under 18 years. Prevalence in adults was 11\% [54/496; 95\% confidence interval (C): 8.3-14.5\%] versus $0 \%$ among children. All but one case were in Bolivians. Diagnosis was independently associated with having been born in Bolivia (aOR: 102, 95\% Cl: 13-781) and a primary school-level education (aOR: 2.40, 95\% Cl: 1.14-5.06). Of 54 people diagnosed with Chagas disease (most of whom were asymptomatic), 42 (77.7\%) returned to the clinic at least once, and 24 (44.4\%) received treatment. Multivariable analysis showed that coming from Argentina (aOR: 13, 95\% Cl: 1.61-1188) or Bolivia (aOR: 1.90, 95\% Cl: 1.19-3.39) and having received information about Chagas disease in Spain (aOR: 4.63, 95\% Cl: 2.54-8.97) were associated with a good level of knowledge on the disease. Having primary level studies (aOR: 0.59, 95\% Cl: 0.34-0.98) and coming from Ecuador (aOR: 4.63, 95\% Cl: 2.52-847) were independently associated with a lower level of knowledge.

\footnotetext{
*Correspondence: jramosrincon@yahoo.es

†Violeta Ramos-Sesma and Miriam Navarro contributed equally to this work

${ }^{5}$ Clinical Medicine Department, University Miguel Hernández of Elche, Sant Joan d'Alacant, Spain

Full list of author information is available at the end of the article
}

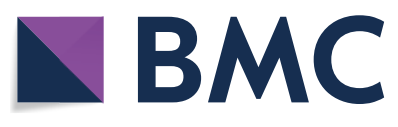

(c) The Author(s) 2021. Open Access This article is licensed under a Creative Commons Attribution 4.0 International License, which permits use, sharing, adaptation, distribution and reproduction in any medium or format, as long as you give appropriate credit to the original author(s) and the source, provide a link to the Creative Commons licence, and indicate if changes were made. The images or other third party material in this article are included in the article's Creative Commons licence, unless indicated otherwise in a credit line to the material. If material is not included in the article's Creative Commons licence and your intended use is not permitted by statutory regulation or exceeds the permitted use, you will need to obtain permission directly from the copyright holder. To view a copy of this licence, visit http://creativecommons.org/licenses/by/4.0/. The Creative Commons Public Domain Dedication waiver (http://creativeco mmons.org/publicdomain/zero/1.0/) applies to the data made available in this article, unless otherwise stated in a credit line to the data. 
Conclusions: Community-based interventions are a good strategy for diagnosing neglected diseases such as Chagas disease in non-endemic countries and for identifying and treating infected, asymptomatic individuals.

Keywords: Chagas disease, Trypanosoma cruzi, Knowledge, Community-based intervention, Migrant, Early diagnosis, Screening

\section{Background}

Chagas disease, or American trypanosomiasis, is a systemic chronic parasitic infection caused by the protozoa Trypanosoma cruzi, considered a neglected tropical disease [1]. Chagas disease is endemic in 21 continental Latin American countries, where vectorial transmission is the main route of contagion [2].

Vector-borne infections occur only in endemic areas, through the inoculation of $T$. cruzi-infected feces of triatomine bugs into the bite wound. Blood transfusion, organ transplantation, mother-to-infant transmission, and ingestion of contaminated food can be other mechanisms of infection [3]. The classic setting for Chagas disease is rural Latin American areas, such as Bolivia, Colombia, Argentina, or Mexico, where an estimated 6 to 7 million people have Chagas disease and another 70 million are at risk of infection [4].

After an initial parasitemia that can last four to eight weeks, the disease becomes chronic. Up to $70 \%$ of infected individuals remain asymptomatic, but they have the parasite and can therefore transmit it through blood transfusions or pregnancy; in non-endemic countries, these are the most frequent transmission routes. Around $30-40 \%$ of cases develop clinical manifestations, especially digestive and cardiological ones. Worldwide, complications derived from the disease lead to about 12000 deaths each year [5].

Approved drugs for treating Chagas disease are benznidazole and nifurtimox, whose efficacy is high during the acute phase (including in congenitally infected newborns) but less so in the chronic phase, when the drugs' effectiveness in preventing disease progression is unclear $[6,7]$. However, recent studies have shown that benznidazole can reduce complications associated with Chagas cardiomyopathy by decreasing the markers of severe cardiomyopathy [8], blood antibodies [9], and mortality [10] and it also is associated with a lower risk of clinical events. Nevertheless, in patients aged older than 55 years, treatment should be individualized to manage the risk of side effects $[6,11]$.

Migration and specific modes of transmission have made Chagas disease a global issue. Spain is the nonendemic country with the highest prevalence of Chagas disease outside the Americas, with an estimated 65000 affected individuals, although less than $10 \%$ have been diagnosed [12-14]. Migrants from Bolivia have the highest prevalence of the disease in Europe [15].

The absence of symptoms and the negligible perception of disease risk play an important role in the health-seeking behavior of the affected population in non-endemic countries. Different community-based interventions and screening campaigns set up in Spain, other European countries, and the United States of America [16-19] have aimed to reach out to Latin American migrants at risk of Chagas disease, provide them with screening and treatment, and minimize access barriers. Offering culturally tailored information about Chagas disease to affected communities is a key component of these strategies.

In view of the above, a screening campaign for Chagas disease was designed in the framework of a communitybased study, performed through a series of workshops. The objective was to assess prevalence of Chagas disease in Latin American migrants attending that event and linkage to care in those with positive screen results. We also evaluate participants' level of knowledge on Chagas disease and examine the effectiveness of the campaign follow-up interventions.

\section{Material and methods Settings}

A community-based screening campaign for Chagas disease and strongyloidiasis was implemented between 2016 and 2018 in Alicante (Spain), a province located on the Mediterranean coast of south-eastern Spain. Around 48 700 migrants from Central and South America are settled in the region [20].

This cross-sectional study had two stages: for the first two years (2016 and 2017), the program was held in the General University Hospital of Alicante, in Alicante city (setting A) and followed up there and in other provincial hospitals. In 2018, the campaign was scaled up into two additional settings, namely, two primary healthcare centers: in Callosa d'en Sarrià, a city located about $40 \mathrm{~km}$ north of Alicante city (setting B) and in Álvarez de la Riva in Orihuela, which is $60 \mathrm{~km}$ to the south (setting C) (Additional file 1: Figure S1). People with positive serology for $T$. cruzi after screening were followed up in the nearest hospital.

This study is part of a larger research project, entitled "Diagnosis, treatment and follow-up of parasitic diseases (Chagas disease and strongyloidiasis) in the province 
of Alicante". The results of the three community-based screening campaigns for strongyloidiasis have recently been reported [21].

\section{Participants}

Inclusion criteria were people from Latin American countries who attended the community-based screening campaigns and signed informed consent. Participants under 18 years of age were included in the Chagas disease screening program if their parents or legal guardian signed the written informed consent, but they were not included in the analysis of disease knowledge. Children born in Spain were included if their parents had been born in Latin America and had travelled to their parents' country of origin.

Exclusion criteria were: refusal to sign informed consent, no available blood sample, born in a country where Chagas disease is not endemic (e.g., Dominican Republic or Cuba), and adult born in Spain (Additional file 1: Figure S2).

\section{Questionnaire on Chagas disease knowledge}

Once participants signed informed consent, they completed a questionnaire collecting sociodemographic data and epidemiological risk factors for $T$. cruzi infection. The questionnaire also tested participants' knowledge of Chagas disease through 15 items, based on previously developed questionnaires aimed at populations at risk of Chagas disease and described in a report published by the Spanish Ministry of Health [22]. All documents were in the Spanish language (Additional file 1: File S1).

After completing the questionnaire, participants were invited to listen to a short informative talk about the disease and to resolve doubts with community health workers and healthcare staff. Finally, peripheral blood was drawn to perform T. cruzi serology. Medical doctors, medical or nursing students and community health workers were always available for assistance.

To assess the factors associated with the participants' level of knowledge about Chagas disease, a knowledge index was calculated according to the study published by Romay-Barja et al. [23]. To create the knowledge index, we selected five facts about Chagas disease that we considered respondents should know: it can be transmitted by triatomines [vinchucas (kissing bugs)] (1 point) or from mother to child (1 point); cardiac involvement is a main consequence of the disease (1 point); digestive disorders constitute the main symptom (1 point); and affected people can be asymptomatic (1 point). Poor knowledge about Chagas disease was defined as the mean score or below. Scores above the mean were considered to indicate a good level of knowledge.

\section{Serology procedure}

Serologic diagnosis of Chagas disease was performed by chemiluminescence immunoassays (CLIA) with Liaison XL Murex Chagas kit (DiaSorin, Saluggia, Italy), and an enzyme-linked immunosorbent assay (ELISA)-in-house method using an antigen prepared from a proportional mix of epimastigotes obtained from a culture of three strains of T. cruzi (MC, T, Dm 28) in stationary phase. Optical density $>1.0$ titer was considered positive. In case of discordant serology, an indirect in-house immunofluorescent antibody test (IFAT) was performed. The antigen was prepared from cultures of epimastigotes in stationary phase. Titers of $1 / 80$ or more were considered positive. A person was considered infected with $T$. cruzi if the results of the two different serological tests on serum samples were positive. Serology was performed at the Parasitology Department of the National Centre for Microbiology-Instituto de Salud Carlos III (PD-NCM-ISCIII) in Madrid.

\section{Management of data after the screening campaign and follow-up of people with Chagas disease}

Participants with a negative $T$. cruzi serology were informed about the results of the test by ordinary mail to the address provided by them. Positive results were traced, and people were offered an appointment at a specialized outpatient clinic. In 2016 and 2017, outpatient consultations took place in the General University Hospital of Alicante as well in other hospitals, while in 2018 participants were followed up in one of the three participating reference hospitals. Participants' full medical history was reviewed, and additional tests were ordered to complete the Chagas disease organ involvement study according to each hospital's protocol. Additional tests could include chest X-ray, electrocardiogram, echocardiography and a molecular diagnostic method [real-time polymerase chain reaction (PCR) Dia.Pro-Diagnostic Bioprobes Srl, Sesto San Giovanni, Italy], among others.

Specific trypanocide treatment was offered to all Chagas disease patients aged 55 years or less, in the absence of contraindication and based on the current evidence $[2,7,9,24]$. Response to treatment was defined as PCR results becoming negative in those patients this test was ordered. If PCR was negative at the beginning of the treatment and remain negative once completed, it was considered cure as well. Positive PCRs following treatment were considered failures [25]. The PCR was repeated between three and 18 months after finished the treatment. Medical records of all screened patients in three different hospitals were last reviewed on 7 December, 2019. 


\section{Statistical analysis}

Categorical data are presented as absolute numbers and proportions, and continuous variables are expressed as either medians and interquartile ranges (IQRs) or means and standard deviation $(S D)$, according to the normality of the distribution. The $95 \%$ confidence intervals $(C I)$ for prevalence were calculated following the methods described by Newcombe et al. [26]. When appropriate, the chi-square test or Fisher's exact test were used to compare the distribution of categorical variables, and the Mann-Whitney $U$ test or student's $t$ test was used for continuous variables. The measure of association was calculated using the odds ratio $(O R)$ with its $95 \% C I$. Results were considered statistically significant if the two-tailed $P$ value was less than 0.05 .

Variables from the crude analysis yielding a $P$ value of less than 0.10, plus age, sex, and time in Spain were entered into a multivariable logistic regression using a forward stepwise selection method with the likelihood ratio test. Model validity was evaluated using the Hosmer-Lemeshow test for estimating goodness of fit to the data and its discriminatory ability using the area under the receiver operating curve (AUC). Because there were some missing values, variables that were not recorded for $25 \%$ or more of the patients were excluded from the analysis. The results of the regression analysis were expressed as adjusted odds ratios (aORs) with 95\% CIs. Statistical data analysis was performed using IBM SPSS Statistics for Windows, Version 250.0 (IBM Corp; Armonk, NY: USA).

\section{Ethical aspects}

All research was conducted according to the principles expressed in the Declaration of Helsinki, and participation was voluntary. The three community-based screening campaigns (2016-2018) were approved by the Ethics Committee of the General University Hospital of Alicante (Valencia Health Council), Ref: CEIC PI2015 /16 and Ref. CEI PI2018/035, and written informed consent was obtained from all participants. The formal written consent was obtained from the parent/guardian in participants aged under 18 years. Performance and reporting of the study comply with STROBE guidelines (Additional file 1: File S2).

\section{Results}

\section{Participants}

Of 616 people screened, 596 were included in the study: 127 in 2016, 111 in 2017 and 358 in 2018 (setting A, $n=124$ participants; setting $\mathrm{B}, n=82$; setting C, $n=152$ ). One hundred (16.8\%) participants were under 18 years of age. Participant characteristics are summarized in
Table 1. Most of the non-adult participants were born in Spain (74\%), while a plurality of the adults was born in Bolivia (41\%).

\section{Prevalence and factors related of Chagas disease}

No cases of Chagas disease were detected in participants under 18 years of age (prevalence 0\%; 95\% CI: 0-4.6\%), while 54 of the 496 adults were positive for T. cruzi infection (prevalence 10.9\%, 95\% CI: 8.3-14.5\%; $P<0.001$ ).

All but one T. cruzi infection were detected in Bolivians. Country of birth in Bolivia and lower educational level were associated with Chagas disease. There were statistically significant differences between participants with or without positive $T$. cruzi serology according to the following variables $(P<0.05)$ : age (median 44 vs 41 years), education to primary school ( $41.5 \%$ vs $25.2 \%$ ), being born in Bolivia (98.1\% vs $37.7 \%$ ), having seen triatomines at home (90\% vs $50 \%$ ), having relatives with Chagas disease ( $42.9 \%$ vs $15.9 \%)$, having heard about Chagas disease (95.2\% vs $50.5 \%$ ), previously underwent Chagas disease serology (25.4\% vs $8.94 \%)$, and having Strongyloides stercoralis-positive serology (25.9\% vs $10.4 \%)$. Being born in Ecuador ( $0 \%$ vs $42.2 \%)$, and Colombia ( $0 \%$ vs $14.7 \%$ ) was associated with a significantly lower risk (Table 2).

After adjusting for age, sex and time in Spain, the multivariable analysis showed that positive T. cruzi serology was associated with being born in Bolivia (aOR: 102, 95\% CI: 13-781) and primary school-level education (aOR: 2.40, 95\% CI: 1.14-5.06; Table 3). In this model, the $P$ value for the Hosmer-Lemeshow test of goodness of fit was 0.99 with an AUC of 0.91 (95\% CI: 0.87-0.93).

\section{Clinical evaluation and management of Chagas disease}

Thirteen of the 54 participants $(24.1 \%)$ had been diagnosed with Chagas disease prior to the campaign. Two of the 54 participants with positive T. cruzi serology were unreachable by phone, and 10 patients did not show up to the consultation. Thus, medical follow-up was performed in 42 patients (77.8\%). Five went to just one appointment, and five more were lost to follow-up after an initial checkup. Thus, no information about the complementary test results was available, so the clinical status of these patients is unknown, and treatment was not offered. Three participants were attended one year after the screening was performed: one from the $2016 \mathrm{cam}$ paign and two from 2017. All of them were finally located and examined by a doctor. Twenty-eight of the 32 (87.5\%) followed patients were asymptomatic, while 4 of them (12.5\%) had Chagasic cardiomyopathy. Of all patients that completed the clinical evaluation (76.2\%), treatment was offered to 24 of them (75\%). Five (15\%) had been treated previously, and three (9\%) were not indicated for medication due to age ( $\geq 55$ years) (Fig. 1 ). 
Table 1 Sociodemographic and epidemiological profile of participating adults and children/adolescents

\begin{tabular}{|c|c|c|}
\hline & Adults, $n / N(\%)^{a}$ & $\begin{array}{l}\text { Children/ } \\
\text { adolescents, } \\
n / N(\%)^{\mathrm{a}}\end{array}$ \\
\hline \multicolumn{3}{|l|}{ Epidemiology and demographic data } \\
\hline Sex, male & 197/496 (39.7) & $43 / 100(43.0)$ \\
\hline Age in years, median (IQR) $(n=488)$ & $41(34-50)$ & $11 / 100(9-14)$ \\
\hline Years in Spain (IQR) $(n=477)$ & $14(11-16)$ & NA \\
\hline \multicolumn{3}{|l|}{ Country of birth } \\
\hline Bolivia & 202/496 (40.7) & $13 / 100(13.0)$ \\
\hline Ecuador & 187/496 (37.7) & $9 / 100(9.0)$ \\
\hline Colombia & $65 / 496(13.1)$ & $0 / 100(0.0)$ \\
\hline Argentina & 13/496 (2.6) & $2 / 100(2.0)$ \\
\hline Brazil & $7 / 496(1.4)$ & $0 / 100(0.0)$ \\
\hline Paraguay & 6/496 (2.6) & 0/100 (0.0) \\
\hline Peru & 4/496 (0.8) & $0 / 100(0.0)$ \\
\hline Venezuela & $4 / 496(0.8)$ & $0 / 100(0.0)$ \\
\hline Other ${ }^{b}$ & $8 / 496(1.6)$ & $2 / 100(2.0)$ \\
\hline Spain $^{c}$ & $-0 / 496(0.0)$ & $74 / 100(74.0)$ \\
\hline Living in rural area & $151 / 201(75.0)$ & NA \\
\hline \multicolumn{3}{|l|}{ Highest educational attainment } \\
\hline Primary school & $128 / 473(27.1)$ & NA \\
\hline Secondary school & $265 / 473(56.0)$ & NA \\
\hline University studies & $80 / 473(16.9)$ & NA \\
\hline \multicolumn{3}{|l|}{ Healthcare card availability } \\
\hline Available & $360 / 368(72.6)$ & NA \\
\hline \multicolumn{3}{|l|}{ Employment status } \\
\hline Actively employed & $347 / 464(70.0)$ & NA \\
\hline Unemployed & $121 / 464(26.1)$ & NA \\
\hline \multicolumn{3}{|l|}{ Occupation } \\
\hline Cleaning services & $83 / 308(16.7)$ & NA \\
\hline Services sector ${ }^{d}$ & $67 / 308(13.5)$ & NA \\
\hline Construction workers & $65 / 308(13.1)$ & NA \\
\hline Farming & 44/308 (8.9) & NA \\
\hline Hospitality/catering & $30 / 308(6.0)$ & NA \\
\hline Caretakers & 19/308 (3.8) & NA \\
\hline \multicolumn{3}{|l|}{ Questions about Chagas disease, $n / N(\%)$ yes } \\
\hline Have you seen triatomines at home? & 108/200 (54.0) & NA \\
\hline Have you ever had a blood transfusion? & 18/199 (14.1) & NA \\
\hline Do you have relatives with Chagas disease? & $38 / 203(18.7)$ & NA \\
\hline Have you ever heard about Chagas disease? & $112 / 203(55.2)$ & NA \\
\hline Have you been tested before? & $58 / 529(11.0)$ & NA \\
\hline
\end{tabular}

IQR interquartile range, $N A$ not available

a Unless otherwise noted, ${ }^{\mathrm{b}}$ Other countries: Mexico $(n=2)$, Honduras $(n=2)$, Nicaragua $(n=2)$, Uruguay $\left(n=2\right.$ adults and $n=2$ children) ${ }^{\mathrm{C}}$ Non-adult Spanish participants whose parents were migrants, ${ }^{\mathrm{d} S e r v i c e}$ sector such as: public health and medical services health care, media and communication, financial services, or transportation)

Of the 54 positives, $29(53.7 \%)$ were women and 18 (33.3\%) were women of childbearing age (18 to 45 years). Of these, $38.9 \%$ (7/18) did not show up to the consultation, while the other 11 were evaluated: 3 (16.7\%) were treated before screening and 8 (44.4\%) afterward.
The screening campaigns in 2016-2017 and 2018 are described separately, as seropositive participants from 2018 were followed up in three different hospitals, while those from 2016 and 2017 were mostly attended in one. Twenty-one patients were diagnosed with Chagas 
Table 2 Comparison of adult participants with positive versus negative Trypanosoma cruzi serology according to sociodemographic and epidemiological variables

\begin{tabular}{|c|c|c|c|}
\hline & T. cruzi positive & T. cruzi negative & $P$ value \\
\hline \multicolumn{4}{|l|}{ Demographic data } \\
\hline Sex, male, $n / N(\%)$ & $27 / 54(50.0)$ & 169/442 (38.2) & 0.09 \\
\hline Age (years), median (IQR) & $44(39-51)$ & $41(34-49)$ & 0.038 \\
\hline Time in Spain (years), median (IQR) & $12.5(11-15)$ & $14(11-16)$ & 0.097 \\
\hline \multicolumn{4}{|l|}{ Education, $n / N(\%)$} \\
\hline Primary school & $22 / 53(41.5)$ & $106 / 420(25.2)$ & 0.012 \\
\hline Secondary school & $26,753(49.1)$ & 239/420 (56.9) & 0.28 \\
\hline University studies & $5 / 53(9.4)$ & 75/420 (17.9) & 0.12 \\
\hline \multicolumn{4}{|l|}{ Country of birth, $n / N(\%)$} \\
\hline Bolivia & $53 / 54(98.1)$ & $149 / 442(37.7)$ & $<0.001$ \\
\hline Ecuador & $0 / 54(0)$ & $187 / 442(42.2)$ & $<0.001$ \\
\hline Colombia & $0 / 54(0)$ & $65 / 442(14.7)$ & 0.003 \\
\hline Argentina & $1 / 54(1.9)$ & $12 / 442(2.7)$ & 0.70 \\
\hline Brazil & $0 / 54(0)$ & $7 / 442(1.6)$ & 0.32 \\
\hline Paraguay & $0 / 54(0)$ & $6 / 442(1.4)$ & 0.38 \\
\hline Peru & $0 / 54(0)$ & 4/442 (0.9) & 0.99 \\
\hline Venezuela & $0 / 54(0)$ & $4 / 442(0.9)$ & 0.99 \\
\hline Othera & $0 / 54(0)$ & $8(1.6)$ & \\
\hline \multicolumn{4}{|l|}{ Epidemiological data, $n / N(\%)$} \\
\hline Living in rural area & $16 / 20(80.0)$ & 135/181 (74.6) & 0.32 \\
\hline Triatomines seen at home & $18 / 20(90.0)$ & $90 / 180(50.0)$ & 0.001 \\
\hline Blood transfusion recipient & $2 / 19(10.5)$ & $26 / 180(14.4)$ & 0.64 \\
\hline Relatives with Chagas disease & 9/21 (42.9) & 29/182 (15.9) & 0.003 \\
\hline Having heard about Chagas disease & $20 / 21(95.2)$ & $92 / 182(50.5)$ & $<0.001$ \\
\hline Positive Strongyloides stercoralis serology & $14 / 54(25.9)$ & $46 / 442(10.4)$ & 0.001 \\
\hline Previously underwent Chagas disease serology & $18 / 53(34.0)$ & $40 / 476(8.4)$ & $<0.001$ \\
\hline
\end{tabular}

IQR interquartile range

aOther countries: Nicaragua $(n=2)$, Uruguay $(n=2)$, Honduras $(n=2)$, Mexico $(n=2)$. In bold, statistically significant differences

disease in those two years. Seventeen attended at least one appointment (81\%), but one (6\%) was lost to followup, so 16 completed clinical evaluation (94.1\%). Treatment was offered to 11 (68.7\%); 4 (25\%) had been treated previously (before joining the campaign), and 1 (6.2\%) did not meet clinical criteria for parasiticidal treatment.

In 2018, 33 infected people were diagnosed: 4 cases in setting A, 16 in setting B, and 13 in setting C. Twentyfive $(75 \%)$ patients attended at least one appointment, but nine (36\%) did not complete the clinical evaluation; four patients (20\%) were lost to follow-up after the initial evaluation. Altogether, 16 people completed the clinical evaluation (64\%). Trypanocide treatment was offered to 13 (81\%); 1 (6\%) had been treated previously, and 2 (12.5\%) were not indicated for treatment (Fig. 2).

\section{Level of knowledge about Chagas disease}

A total of $98.3 \%(488 / 496)$ adult participants included in the study completed the 15 -item survey. Not all participants answered the survey questions included in the score. Table 4 shows the survey results.

More than half $(64.3 \%)$ of the surveyed participants knew about the vectorial route of transmission, and nearly $40 \%$ could correctly respond to the item related to the vertical transmission route. Regarding organ involvement, $48.8 \%$ of participants knew that Chagas disease can affect the heart, but only $27.4 \%$ were aware of the potential involvement of the digestive tract, and just $27.7 \%$ knew that the disease could be asymptomatic (Table 4).

For most items, Bolivians were more knowledgeable than people from other countries; participants with positive $T$. cruzi serology, more so than participants with negative results (Table 4); and people who had attained a higher educational level, more so than those with less schooling (Additional file 1: Table S1). When analyzing the level of the knowledge by gender, women were more aware of the heart involvement ( $52.5 \%$ vs $43.0 \% ; P=0.03$ ), but there were no statistically significant differences 
Table 3 Association between sociodemographic and epidemiological characteristics with positive and negative Trypanosoma cruzi serology (crude and multivariable analysis)

\begin{tabular}{|c|c|c|c|}
\hline Variables & Crude $O R(95 \% C l)$ & Adjusted $O R(95 \% C l)$ & $P$ value \\
\hline Sex, male & $1.65(0.92-2.82)$ & $1.58(0.77-3.23)$ & 0.21 \\
\hline Age, years & $1.02(1.00-1.53)$ & $1.02(0.99-1.06)$ & 0.11 \\
\hline Time in Spain, years & $0.97(0.92-1.02)$ & $1.01(0.93-1.08)$ & 0.89 \\
\hline Primary school & $2.10(1.16-2.78)$ & $2.40(1.14-5.06)$ & 0.021 \\
\hline \multicolumn{4}{|l|}{ Country of birth } \\
\hline Bolivia & $104(14.2-761)$ & $102(13-781)$ & $<0.001$ \\
\hline Ecuador & NC & $\mathrm{NI}$ & \\
\hline Colombia & NC & $\mathrm{NI}$ & \\
\hline Living in rural area & $1.36(0.43-4.28)$ & $\mathrm{NI}$ & \\
\hline Triatomines seen at home & $9.0(2.03-39.9)$ & $\mathrm{NI}$ & \\
\hline Blood transfusion recipient & $0.69(0.15-3.19)$ & $\mathrm{NI}$ & \\
\hline Relatives with Chagas disease & $3.95(1.53-10.2)$ & $\mathrm{NI}$ & \\
\hline Having heard about Chagas disease & $19.5(2.57-148)$ & $\mathrm{Nl}$ & \\
\hline Positive Strongyloides stercoralis serology & $3.01(1.53-5.95)$ & $2.28(0.96-5.46)$ & 0.062 \\
\hline Previously underwent Chagas disease serology & $5.61(2.91-10.8)$ & $2.12(0.98-4.50)$ & 0.054 \\
\hline
\end{tabular}

In bold, statistically significant differences; NC Not calculable, OR Odds ratio. CI Confidenceinterval, NI Not included

regarding knowledge on the vertical transmission route (Additional file 1: Table S1).

The mean knowledge index about Chagas among 488 participants was $1.7 \pm 1.7$. Argentinians, as a group, were the most knowledgeable $(2.8 \pm 0.9)$, followed by people with relatives infected with Chagas disease $(2.7 \pm 1.6)$, and those who received information about the disease in Spain (2.7 \pm 1.6$)$ (Table 5). Additional file 1: Table S2 shows the variables associated with a good level of knowledge about Chagas disease (score $>2$ points) in the bivariable analysis. In the multivariable analysis, only being from Bolivia or Argentina and having received information about Chagas disease in Spain were associated with a good level of knowledge. On the other hand, primary-level studies and being from Ecuador were associated with poorer knowledge (Table 6).

In the subgroup of Bolivians $(n=198)$, the mean score was $2.2 \pm 1.6$, with $44.9 \%$ showing good knowledge about Chagas disease. In the bivariable analysis, two variables were associated with good knowledge scores: having heard about Chagas $(64.9 \%$ vs $0.0 \% ; P=0.004)$ and having received information about the disease in Spain $(72.5 \%$ vs $37.4 \%, P<0.001)$.

\section{Discussion}

Our study showed that one of 10 participants in our screening program have Chagas disease, slightly higher than the pooled prevalence reported in a recent systematic review of Chagas disease in migrants in Europe $[18,27]$. All except one came from Bolivia, so one of five Bolivians had Chagas disease. In fact, the factor most strongly associated with Chagas disease was being born in Bolivia. These results are consistent with other community-based seroprevalence studies [18, 27, 28]. People who had stopped studies after primary school were also at higher risk of having Chagas disease, in keeping with other studies of T. cruzi antibodies in blood donors in endemic countries [29]. This finding can be linked with the tendency for the disease to affect people with limited resources.

Indeed, Chagas disease is endemic to Latin America and is linked to disadvantaged and poor populations [1]. Pane et al. [27] described housing conditions and building materials as statistically significant factors for acquiring the disease. Close contact with infected animals also favors transmission of the disease [30]. Traditionally associated with rural areas, in recent decades Chagas disease has also been detected in urban settings. Migration from the countryside to the city has favored the growth of urban centers and the appearance of slums [31]. The main control strategies are based on vector control and housing improvements [30]. However, public awareness, an active search for infected persons, and an investment of resources to enable access to the health system and treatment are also key. Each of these barriers presents a unique public health challenge [32]. The persistence of Chagas disease is linked to social, cultural, historical, political and economic processes [30].

One out of four participants with Chagas disease in our study was co-infected with $S$. stercoralis, which is in keeping with the co-infection prevalence of $21 \%$ reported in another Spanish Collaborative Network [33, 34]. 


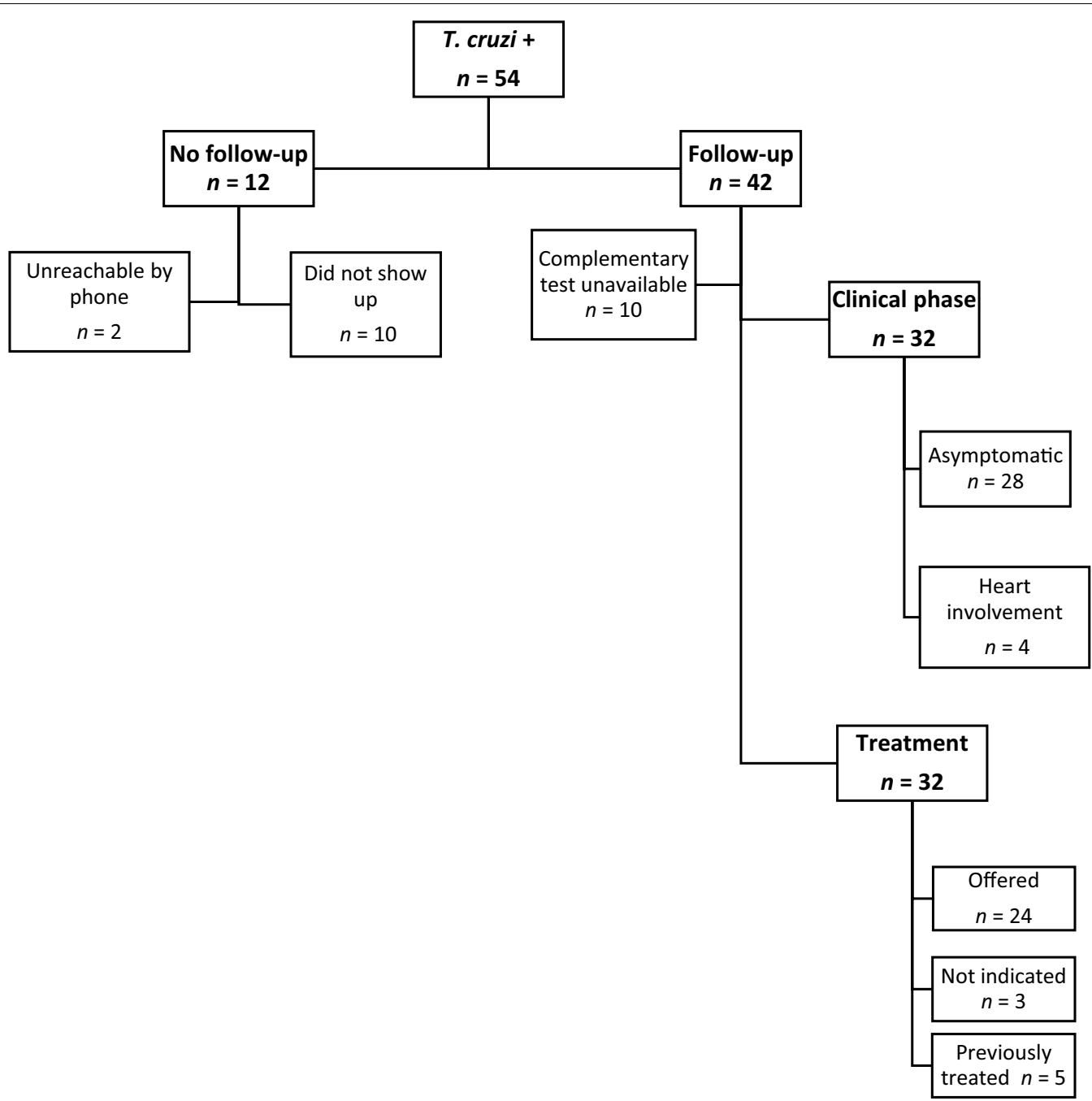

Fig. 1 Three years campaigns'follow chart of the clinical evaluation and management of participants with positive Trypanosoma cruzi serology

Of the patients who attended the screening, only $11 \%$ had previously undergone serology. A quarter of the participants infected by $T$. cruzi had already tested positive before screening, and $15 \%$ had already been treated. Despite this, these participants joined the campaign freely in order to be re-tested. They may not have known about the chronic course of the disease, potentially receiving limited information at the time of the previous test. According to Parsi et al. [35] even after health campaigns in endemic areas, persistent knowledge gaps and misconceptions of serologic test results remain and contribute to creating structural barriers, leading to the normalization and acceptance of Chagas disease and its social consequences. Our campaign suggests that ease of access (testing on weekends, all activities free and freely offered to all) may help to convince people to come to the screening.
Regarding follow-up during the three campaigns, 75\% of individuals with positive screening results attended their first medical appointment. As expected, most were in the chronic asymptomatic phase of the disease, and around $75 \%$ of them were offered the pharmacological treatment by the time the medical histories were reviewed.

In spite of the advantages of treatment, its administration is inherently complex, since it involves taking several pills twice a day for a recommended time of 60 days. In addition, its use is associated with very frequent adverse effects, which, although mild, sometimes make it necessary to suspend treatment [36]. In endemic areas, these challenges come on top of problems with financing and access to medication [32]. However, with proper coordination between health care services, diagnosis and treatment can be safely implemented even in remote areas. 


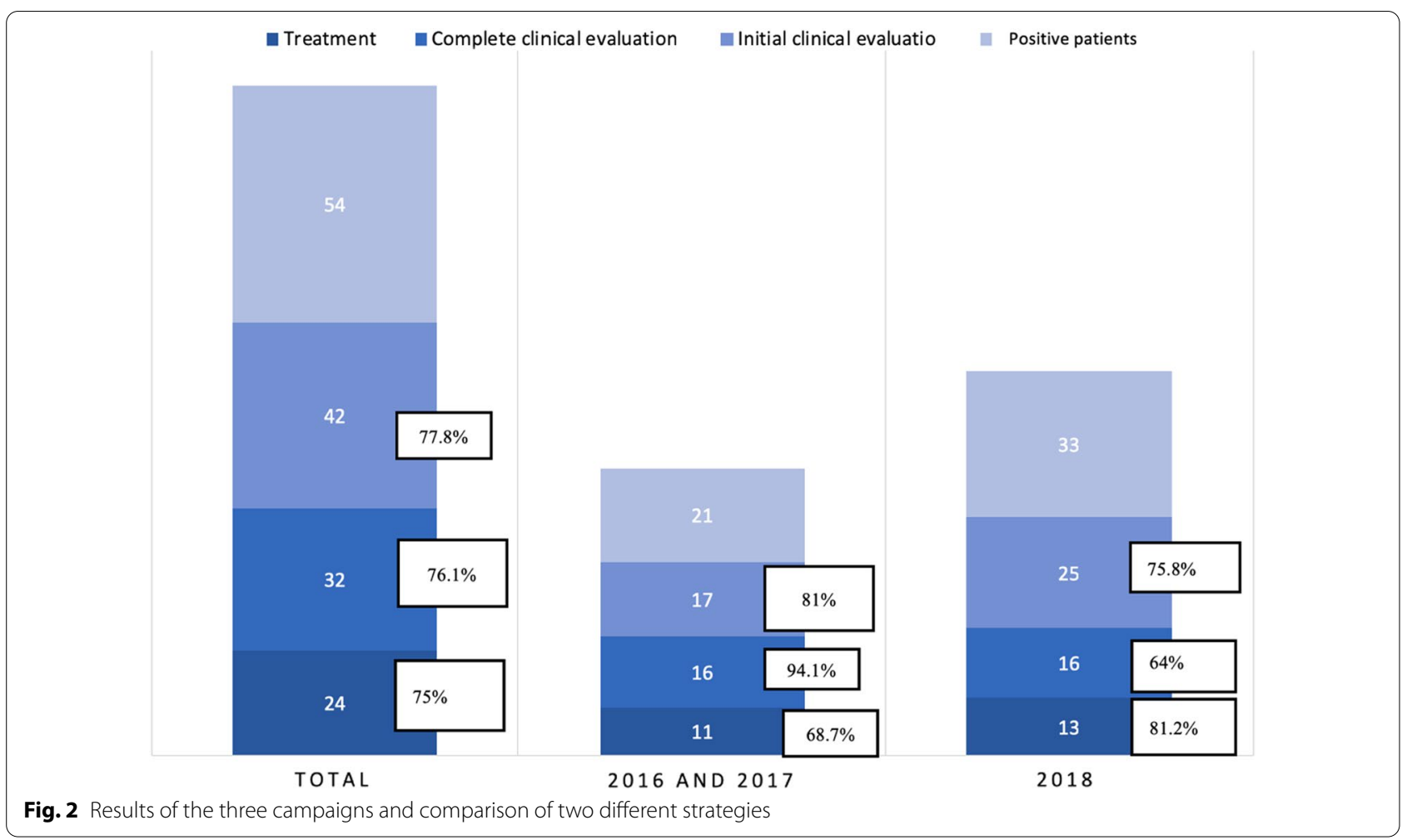

Yun et al. [37] sets out an example of implementing Chagas disease diagnosis and treatment program in resourcelimited settings, including remote rural areas, while addressing the limitations associated with drug-related adverse events.

Other studies, like the one by Repetto et al. [38], have reported that less than $30 \%$ of participants completed the treatment. Other community-based campaigns that assessed uptake in the screened population show similar data, with a remarkable loss to follow-up: around $50 \%$ of diagnosed patients did not begin treatment $[39,40]$.

Based on the experience in 2016 and 2017, the 2018 campaign was simultaneously organized in three different settings in order to reach more people. This last campaign was successful in terms of engaging a higher number of participants than in the two previous meetings, resulting in a higher number of diagnoses in 2018 compared to the first two years (33 in 2018 vs 21 in 2016-2017). Follow-up of positive-screened individuals was not centralized in a single health care center, as in 2016 and 2017, which could have facilitated access to follow-up and treatment. However, despite the increased access points for follow-up and our best efforts to minimize attrition, a higher number of participants were lost in the final edition.

The phase following campaign implementation was quite challenging, especially in 2018, when more people attended. Participants' contact details were not always properly collected, and some resided outside Alicante province, among other complications. It seems reasonable that in the 2018 campaign, fewer participants completed the clinical evaluation because of the proximity between the campaign and the data collection.

Globally, migrants face different barriers in attending medical appointments, including precarious jobs, long working hours, and high mobility within and between countries [40-42]. Different strategies have been proposed to avoid loss to follow-up, such administering treatment during the first medical visit, minimizing visits to the hospital, tracing patients with high mobility, and improving communication vertically (primary-hospital care) and horizontally (between hospitals) [17, 43, 44]. Our experience has taught us that the right timing (e.g. avoiding months when migrants typically travel to their countries of origin) is crucial for ensuring participation and reducing time lapses between the event and the first medical visit.

Community screening campaigns are a useful tool for the diagnosis of asymptomatic people. Not only are they a diagnostic strategy, they can also educate the population and raise awareness of the disease as well as bring people closer to the healthcare system and treatment. In addition, these screening programs are typically organized outside working hours to facilitate access to a larger 
Table 4 Knowledge about Chagas diseases in Bolivians versus non-Bolivians and by Trypanosoma cruzi serology

\begin{tabular}{|c|c|c|c|c|c|}
\hline \multirow[t]{2}{*}{ Questions about Chagas disease } & \multirow[t]{2}{*}{ Total } & \multirow{2}{*}{$\begin{array}{l}\text { Country of birth } \\
\text { Bolivia }\end{array}$} & \multicolumn{3}{|l|}{ Results of $T$. cruzi serology } \\
\hline & & & Other Latin American countries & Positive & Negative \\
\hline \multicolumn{6}{|l|}{ Transmission (right answer), n/N (\%) } \\
\hline $\begin{array}{l}\text { Can Chagas disease be transmitted by an } \\
\text { insect bite? }\end{array}$ & $310 / 482(64.3)$ & $151 / 195(77.4)$ & $159 / 287(55.4)^{\ddagger}$ & $45 / 54(83.9)$ & $265 / 428(61.9)^{\dagger}$ \\
\hline $\begin{array}{l}\text { Can Chagas disease be transmitted by } \\
\text { kissing bugs? }\end{array}$ & $147 / 476(30.9)$ & $101 / 193(52.3)$ & $46 / 283(16.3)^{\ddagger}$ & $28 / 54(51.9)$ & $119 / 422(28.2)^{\dagger}$ \\
\hline $\begin{array}{l}\text { Can Chagas disease be transmitted } \\
\text { through blood transfusions? }\end{array}$ & 135/448 (30.1) & $72 / 183(39.3)$ & $63 / 265(23.8)^{\ddagger}$ & $23 / 52(41.2)$ & $112 / 386(28.3)^{*}$ \\
\hline $\begin{array}{l}\text { Can Chagas disease be transmitted from } \\
\text { mother to child? }\end{array}$ & $179 / 450(39.8)$ & $89 / 182(48.9)$ & $90 / 178(33.6)^{\dagger}$ & 28/51 (54.9) & $151 / 399(37.9)$ \\
\hline $\begin{array}{l}\text { Can Chagas disease be transmitted } \\
\text { through organ transplantation? }\end{array}$ & $95 / 441(21.5)$ & $43 / 178(24.2)$ & $52 / 263(19.8)$ & $13 / 49(26.5)$ & $82 / 392(20.9)$ \\
\hline $\begin{array}{l}\text { Can Chagas disease be transmitted } \\
\text { through sexual contact? }\end{array}$ & $126 / 446(28.3)$ & $54 / 182(35.7)$ & $81 / 264(23.1)^{\dagger}$ & $15 / 51(29.4)$ & $111 / 395(28.1)$ \\
\hline $\begin{array}{l}\text { Can Chagas disease be transmitted } \\
\text { through by kissing? }\end{array}$ & $159 / 445(35.7)$ & $84 / 182(45.2)$ & $75 / 263(28.5)^{\ddagger}$ & 26/51 (51.0) & 133/394 (33.8) \\
\hline $\begin{array}{l}\text { Can Chagas disease be transmitted by liv- } \\
\text { ing with a person who has the disease? }\end{array}$ & $143 / 446(32.1)$ & $79 / 181(43.6)$ & $64 / 265(24.2)$ & $23 / 51(45.1)$ & $120 / 395(30.4)^{*}$ \\
\hline \multicolumn{6}{|l|}{ Clinical characteristics (right answer), n/N (\%) } \\
\hline Can Chagas disease affect the heart? & 238/488 (48.8) & $129 / 198(65.2)$ & $109 / 290(37.6)^{\ddagger}$ & $39 / 54(72.3)$ & $199 / 434(45.9)^{\dagger}$ \\
\hline $\begin{array}{l}\text { Can Chagas disease affect the stomach } \\
\text { and bowels? }\end{array}$ & $129 / 471(27.4)$ & $55 / 188(29.39$ & $74 / 283(26.1)$ & $14 / 49(28.6)$ & $115 / 422(27.3)$ \\
\hline $\begin{array}{l}\text { Can someone with C Chagas disease feel } \\
\text { okay (asymptomatic)? }\end{array}$ & $131 / 473(27.7)$ & $57 / 189(30.2)$ & $74 / 284(26.1)$ & $17 / 50(34.0)$ & $114 / 423(27.0)$ \\
\hline Is Chagas disease a serious disease? & $289 / 482(60)$ & $144 / 192(75.0)$ & $145 / 290(50.0)^{\ddagger}$ & $37 / 51(72.5)$ & $252 / 162(58.5)$ \\
\hline \multicolumn{6}{|c|}{ Diagnosis and treatment (affirmative answer), $n / N(\%)$} \\
\hline Is there diagnosis for Chagas disease? & $172 / 399(43.1)$ & $89 / 196(53.6)$ & $83 / 233(35.0)^{\ddagger}$ & $152 / 359(42.2)$ & $20 / 40(50)$ \\
\hline Is there treatment for Chagas disease? & $252 / 470(53.6)$ & $122 / 189(64.6)$ & $130 / 281(46.3)^{\ddagger}$ & $214 / 419(51.1)$ & $38 / 51(74.5)^{\dagger}$ \\
\hline Does Chagas disease have a cure? & $158 / 458(34.5)$ & $65 / 183(35.5)$ & $93 / 275(33.8)$ & $139 / 409(34.0)$ & 19/49 (38.8) \\
\hline
\end{tabular}

In bold, statistically significant differences: ${ }^{*} P$-value $<0.05 ;{ }^{\dagger} P$-value $<0.01 ;{ }^{\ddagger} P$-value $<0.001$

number of people or at events organized by vulnerable communities. Imaz-Iglesia et al. [45] indicates that the active search for infected patients is a cost-effective strategy, especially in women of childbearing age.

These programs reach a significant number of people who undergo serology, and they are often paired with appropriate strategies to get those diagnosed to attend their medical appointments. However, the programs often lack governmental support and are carried out by health professionals working on a voluntary basis. The absence of support from institutions or hospitals can lead to the aforementioned loss of patients during followup, since specific consultations are not available, which means an extra effort for the physician.

This is one of the few published quantitative studies focused on the knowledge of Chagas disease in Latin American migrants in Europe and other non-endemic regions. Overall, at-risk populations lack awareness of the disease in non-endemic countries $[17,18]$. Ten percent of the participants reached the maximum score of 5 points on the knowledge index, but most scores were below the mean. Among the nearly 200 Bolivian respondents, the mean score (2.2) was above the mean for the whole sample (1.7). This can be attributed to the generalized health education campaigns in Bolivia over the past decades, as this is currently the country with the highest burden of Chagas disease. On the other hand, more than half the Bolivian participants showed poor knowledge on Chagas disease, in line with similar results published recently by Ronay-Barja et al. [23] in Madrid and other authors in Spain and Europe, who also report that most people with Chagas disease are from Bolivia [15, 46, 47]. This highlights the need for continuing community-based interventions in order to improve Chagas disease awareness within the population at risk. Fortunately, one factor associated with better knowledge of Chagas disease was "having received information about the disease in Spain." This highlights the efficacy of the specific information and community-based activities performed across this non-endemic country.

In our setting, where vectorial transmission is not currently possible, few surveyed participants were 
Table 5 Mean score (0-5) for survey on general facts about the disease, by sociodemographic indicators

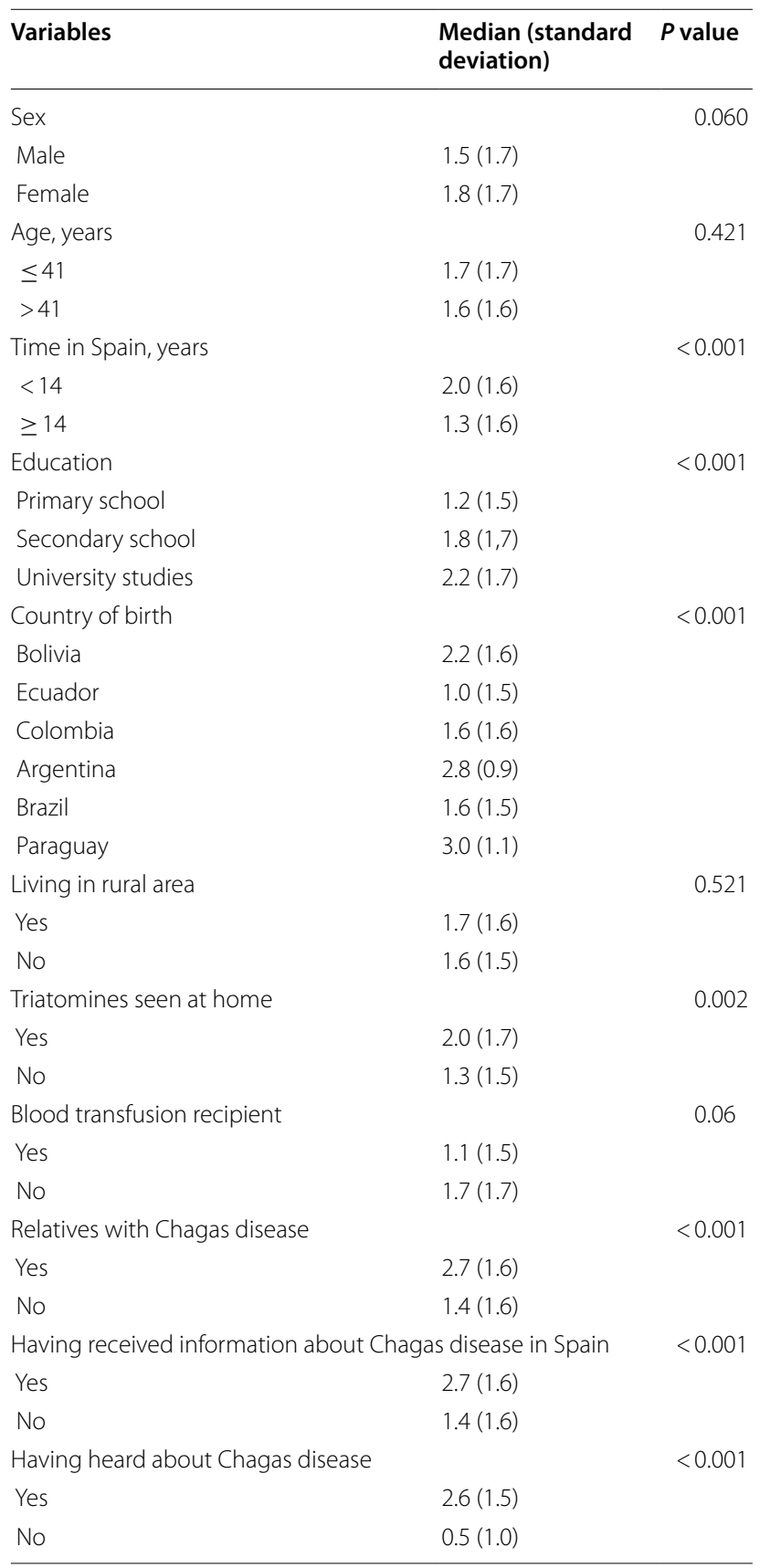

familiar with that route. These data are consistent with other published studies, which report similar percentages to ours in at-risk populations, both in endemic and non-endemic countries [17, 44, 48]. The vertical transmission route, which is the most relevant in nonendemic areas, has prompted governments to establish protocols for the early detection and treatment of neonatal infections [49-52], although much work remains to be done in this context [28, 51-53].

As mentioned above, the general level of knowledge was low, and few participants responded correctly on the routes of transmission. Women were slightly more aware about vertical transmission than men, although the difference was not statistically significant. This finding suggests an opportunity, as training women from endemic areas could add value to interventions focused on congenital Chagas disease. Indeed, our prior experience has underlined that collaboration with female community health workers can be an important determinant of success of community-based interventions in this area [54].

Less than $30 \%$ of participants were aware of the asymptomatic nature of this parasitic infection, one of the main causes of underdiagnosis[16, 35, 40, 55]. Lack of knowledge on Chagas disease in both at-risk populations and healthcare professionals, fear, stigma, and structural barriers are likewise contributing to Chagas disease underdiagnosis $[13,56]$. Regarding the educational level, participants who had attained a higher educational level also had a better understanding of the disease.

Strengths of this research include its three-year study period, which enabled us to assess temporal differences in patient profile, diagnosis, and patient follow-up. However, it also has several limitations. First, it used a crosssectional design, and the setting in a single Spanish province may reduce its generalizability to populations settled in other regions. Most of our participants came from Bolivia, so our sample is less representative of other Latin American countries. However, we consider this to be a strength of the program rather than a limitation: our message and activities are reaching the population that is at the highest risk of Chagas disease in Europe [15]. Second, we encountered some difficulties, discussed above, in following up positive-screened participants. Thirdly, there was no standard Chagas disease protocol in the different healthcare centers where treatment and medical follow-up took place. Lastly, our questionnaire was not validated; it was designed based on a questionnaire used by another Spanish research group $[15,22]$.

\section{Conclusions}

The community-based intervention implemented in Spain is an effective way of providing access to Chagas disease diagnosis and treatment in vulnerable populations. Work is still needed to develop effective strategies that minimize attrition in order to accompany all patients through the process and to offer them treatment. These activities could contribute to preventing infections in newborns and avoiding organ system complications and suffering in people with chronic infections. Efforts are still needed to raise awareness of Chagas disease, 
Table 6 Association between sociodemographic/epidemiological characteristics and a good level of knowledge about Chagas disease (crude and multivariable analysis)

\begin{tabular}{|c|c|c|c|}
\hline Variables & Crude $O R(95 \% C I)$ & Adjusted $O R(95 \% \mathrm{Cl})$ & $P$ value \\
\hline Sex, male & $0.70(0.48-1.01)$ & $0.73(0.47-1.13)$ & 0.17 \\
\hline Age, years & $0.98(0.97-1.00)$ & $0.99(0.97-1.01)$ & 0.31 \\
\hline Time in Spain, years & $0.93(0.89-0.93)$ & $0.97(0.93-1.01)$ & 0.18 \\
\hline Primary school & $0.43(0.28-0.66)$ & $0.59(0.34-0.98)$ & 0.044 \\
\hline University studies & $1.77(1.09-2.90)$ & $1.51(0.85-2.67)$ & 0.11 \\
\hline Country of birth, Bolivia & $2.79(1.91-4.04)$ & $1.90(1.19-3.39)$ & 0.020 \\
\hline Country of birth, Ecuador & $0.24(0.16-0.36)$ & $0.51(0.28-0.94)$ & 0.031 \\
\hline Country of birth, Colombia & $0.89(0.52-1.51)$ & $\mathrm{Nl}$ & \\
\hline Country of birth, Argentina & $12.58(1.61-98)$ & $13(1.61,1.18)$ & 0.017 \\
\hline Living in rural area & $1.61(0.83-3.18)$ & $\mathrm{NI}$ & \\
\hline Triatomines seen at home & $0.48(0.27-0.85)$ & $\mathrm{Nl}$ & \\
\hline Blood transfusion recipient & $0.49(0.21-1.14)$ & $\mathrm{Nl}$ & \\
\hline Relatives with Chagas disease & $4.58(2.15-10.9)$ & $\mathrm{NI}$ & \\
\hline $\begin{array}{l}\text { Having received information about Chagas disease in } \\
\text { Spain }\end{array}$ & $4.38(2.57-7.44)$ & $4.63(2.53,8.47)$ & 0.023 \\
\hline Having heard about Chagas disease & $14.1(7.01-29.7)$ & $\mathrm{Nl}$ & \\
\hline
\end{tabular}

In bold, statistically significant differences. NI Not included

especially in adults from Bolivia and Latin American women of childbearing age.

\section{Abbreviations}

aOR: Adjusted odds ratio; CLIA: Chemiluminescence immunoassays; ELISA: Enzyme-linked immunosorbent assay; IQR: Interquartile range; IFAT: Immunofluorescent antibody test; OR: Odds ratio; PD-NCM-ISCIII: National Centre for Microbiology-Instituto de Salud Carlos III (PD-NCM-ISCIII); NC: Not calculable; NI: Not included; SD: Standard deviation.

\section{Supplementary Information}

The online version contains supplementary material available at https://doi. org/10.1186/s40249-021-00897-2.

Additional file 1: Figure S1. Map of the region showing the three cities where the community-based screening campaigns were performed. In 2016 and 2017 the program was held in Alicante city (setting A) and in 2018, the campaign was scaled up into two primary healthcare centers in Callosa d'en Sarrià, a city located about $40 \mathrm{~km}$ north of Alicante city (setting B) and Álvarez de la Riva in Orihuela, which is $60 \mathrm{~km}$ to the south (setting C). Figure S2. Participant flow chart. File S1. Questionnaire given to participants with sociodemographic data, epidemiological risk factors for T.cruzi infection, knowledge and beliefs on CD (Spanish version). File S2. STROBE Statement-Checklist of items that should be included in reports of cross-sectional studies. Table S1. Knowledge about Chagas diseases (CD) by sex and educational level. Table $\mathbf{S 2}$. Level of knowledge according to sociodemographic factors.

\section{Acknowledgements}

The authors thank all participants of this study and the following institutions: health departments of Alicante, Vega Baja y Marina Baixa (Health Council, Generalitat Valenciana), Fundación Mundo Sano, Salud Entre Culturas, NGO Vega Baja Acoge, Centro de Transfusión Comunidad Valenciana-Alicante, the Consulate of the Plurinational State of Bolivia in the Valencian Community, Spain; and the Chagas disease patients' associations in the regions of Valencia (ACHACOVA) and Murcia (ASAPECHAMUR). Last but not least, we would like to thank the following people for their support: the community health workers specialized in Chagas disease, especially Marleny Molina, Briggitte Jordan and Marcela González for coordinating the institutional and media communication strategy.

We also want to thank to all members of \#CorazonesSinChagas Platform for their active contribution to the program for the past years. We also express our thanks to Meggan Harris for her assistance in editing.

Members of the Corazones Sin Chagas Platform: María García-López, Cristina Bernal-Alcaraz, Pedro B. Guevara-Hernández, Jara Llenas-García, Joan Gregori-Colome, Ana Lucas-Dato, Esther Martínez-Birlanga \& Estefanía García-Rodríguez (Hospital Vega Baja, Orihuela); José-Manuel Ramos Rincón, Diego Torrús-Tendero, Ma Paz Ventero-Martín, Adelina Gimeno-Gascón, Ares Sánchez-Sánchez, Roser Muñoz-Pérez, Carmen Almoedo-Albero (Hospital General Universitario de Alicante), Concepción Gil-Anguita, , Concepción Amador Prous, Ana-Isabel Pujades-Tárraga, Antonio Santonja, María SánchezValera, \& Rosa Sánchez-García (Hospital Marina Baixa Villajoyosa), Miriam Navarro-Beltrá (Universidad Miguel Hernández)

\section{Authors' contributions}

JMRR, MN, \& VRS contribute on study design, data acquisition, study implementation, analysis and implementation of data, major contribution to writing, read an approved final version. JLG contribute equally on study design, analysis and implementation of data, major contribution to writing, read an approved final version. CGA, DTT, NHL, MGL, CAP, PGH, AGS, ASS, CBA, AIPT, PWJ \& RMP contributed equally on data acquisition, study implementation, read and approved final version. MPVM \& MFC analysis and implementation of data, read and approved final version read and approved final version. All authors read and approved the final manuscript.

\section{Funding}

This study was partially supported by the third call for research grants (J-M.R.R.) from the Institute of Health and Biomedical Research of Alicante (ISABIAL)/ FISABIO Foundation (III convocatoria de ayudas a proyectos de investigación del Instituto de Investigación Sanitaria y Biomédica de Alicante (ISABIAL) - Fundación FISABIO) (UGP-16-158); and by the collaborative agreement between ISABIAL/ Fundación FISABIO and Fundación Mundo Sano-Spain, in accordance with the Sponsorship Law. The funders had no role in study design, data collection and analysis, decision to publish, or preparation of the manuscript. 


\section{Availability of data and materials}

The datasets analyzed are available in https://github.com/jramosrincon/Chaga sscreeninng.

\section{Declarations}

\section{Ethics approval and consent to participate}

All research was conducted according to the principles expressed in the Declaration of Helsinki, and participation was voluntary. The three community-based screening campaigns (2016-2018) were approved by the Ethics Committee of the General University Hospital of Alicante (Valencia Health Council), Ref: CEIC PI2015 /16 and Ref. CEI PI2018/035, and written informed consent was obtained from all participants.

\section{Consent for publication}

Not applicable.

\section{Competing interests}

The authors declare that they have no conflict of interest.

\section{Author details}

${ }^{1}$ Internal Medicine Service, HLA Inmaculada Hospital, Granada, Spain. ${ }^{2}$ Public Health, Science History and Gynecology Department, Universidad Miguel Hernández de Elche, Alicante, Spain. ${ }^{3}$ Epidemiology Unit Public Health Center of Elche, Alicante, Spain. ${ }^{4}$ Internal Medicine Department, Hospital Vega Baja de Orihuela (Alicante, Spain)-Foundation for the Promotion of Health and Biomedical Research of the Valencia Region (FISABIO), Alicante, Spain. ${ }^{5}$ Clinical Medicine Department, University Miguel Hernández of Elche, Sant Joan d'Alacant, Spain. ${ }^{6}$ Internal Medicine Department, Hospital Marina BaixaLa Vila Joiosa (Alicante, Spain)-FISABIO, Alicante, Spain. ${ }^{7}$ Internal Medicine Department, General University Hospital of Alicante-Biomedical and Health Research Institute of Alicante (ISABIAL), Alicante, Spain. ${ }^{8}$ Parasitology Area, University Miguel Hernández of Elche, Sant Joan d'Alacant, Spain. ${ }^{9}$ Internal Medicine Department, University Hospital of Sant Joan, (Sant Joan d'Alacant, Spain)- FISABIO, Alicante, Spain. ${ }^{10}$ Microbiology Service, General University Hospital of Alicante-ISABIAL, Alicante, Spain. ${ }^{11}$ Pediatric Department, General University Hospital of Alicante-ISABIAL, Alicante, Spain. ${ }^{12}$ Digestive Service, General University Hospital of Alicante-ISABIAL, Alicante, Spain. ${ }^{13}$ Reference and Research Laboratory in Parasitology, National Center of Microbiology/ Mundo Sano Foundation, Madrid, Spain.

Received: 25 June 2021 Accepted: 24 Auqust 2021

Published online: 15 September 2021

\section{References}

1. Molyneux DH, Savioli L, Engels D. Neglected tropical diseases: progress towards addressing the chronic pandemic. Lancet. 2017;389(10066):31225. https://doi.org/10.1016/S0140-6736(16)30171-4.

2. Pérez-Molina JA, Molina I. Chagas disease. Lancet. 2018;391:82-94. https://doi.org/10.1016/S0140-6736(17)31612-4.

3. Rassi A Jr, Rassi A, Marin-Neto JA. Chagas disease. Lancet. 2010;375:1388402. https://doi.org/10.1016/S0140-6736(10)60061-X.

4. Antinori S, Galimberti L, Bianco R, Grande R, Galli M, Corbellino M. Chagas disease in Europe: a review for the internist in the globalized world. Eur J Inter Med. 2017;43:6-15. https://doi.org/10.1016/j.ejim.2017.05.001.

5. Cucunubá ZM, Okuwoga O, Basáñez MG, Nouvellet P. Increased mortality attributed to Chagas disease: a systematic review and meta-analysis. Parasit Vectors. 2016;9:42. https://doi.org/10.1186/s13071-016-1315-x.

6. Bern C. Chagas' disease. N Engl J Med. 2015;373:456-66. https://doi.org/ 10.1056/NEJMra1410150

7. Norman FF, López-Vélez R. Chagas disease: comments on the 2018 PAHO Guidelines for diagnosis and management. J Travel Med. 2019. https:// doi.org/10.1093/jtm/taz060.

8. Cardoso CS, Ribeiro ALP, Oliveira CDL, Oliveira LC, Ferreira AM, Bierrenbach $A L$, et al. Beneficial effects of benznidazole in Chagas disease: NIH SaMi-Trop cohort study. PLoS Negl Trop Dis. 2018;12(11): e0006814. https://doi.org/10.1371/journal.pntd.0006814.
9. Vallejo M, Reyes PP, Martinez Garcia M, Gonzalez Garay AG. Trypanocidal drugs for late-stage, symptomatic Chagas disease (Trypanosoma cruzi infection). Cochrane Database Syst Rev. 2020;12(12):D004102. https://doi. org/10.1002/14651858.CD004102.pub3.

10. Kratz JM. Drug discovery for chagas disease: a viewpoint. Acta Trop. 2019;198: 105107. https://doi.org/10.1016/j.actatropica.2019.105107.

11. Bern C, Montgomery SP, Herwaldt BL, Rassi A, Marin-Neto JA, Dantas RO, et al. Evaluation and treatment of chagas disease in the United States: a systematic review. JAMA. 2007;298:2171-81. https://doi.org/10.1001/ jama.298.18.2171.

12. Schmunis GA, Yadon ZE. Chagas disease: a Latin American health problem becoming a world health problem. Acta Trop. 2010;115:14-21. https://doi.org/10.1016/j.actatropica.2009.11.003.

13. Requena-Méndez A, Aldasoro E, de Lazzari E, Sicuri E, Brown M, Moore DAJ, et al. Prevalence of Chagas disease in Latin-American migrants living in Europe: a systematic review and meta-analysis. PLoS Negl Trop Dis. 2015;9(2): e0003540. https://doi.org/10.1371/journal.pntd.0003540.

14. Bern C, Montgomery SP. An estimate of the burden of Chagas disease in the United States. Clin Infect Dis. 2009;49(5):e52-4. https://doi.org/10 1086/605091.

15. Navarro M, Perez-Ayala A, Guionnet A, Perez-Molina JA, Navaza B, Estevez $L$, et al. Targeted screening and health education for Chagas disease tailored to at-risk migrants in Spain, 2007 to 2010. Euro Surveill. 2011;16:19973. https://doi.org/10.2807/ese.16.38.19973-en.

16. Romay-Barja M, Boquete T, Martinez O, Gonzalez M, del Arco DA, Benito A et al. Chagas screening and treatment among bolivians living in madrid, Spain: The need for an official protocol. PLoS One. 2019;14:e0213577. https://doi.org/10.1371/journal.pone.0213577.

17. Navarro M, Berens-Riha N, Hohnerlein S, Seiringer P, von Saldern C, Garcia S, et al. Cross-sectional, descriptive study of Chagas disease among citizens of Bolivian origin living in Munich, Germany. BMJ Open. 2017;7:e013960. https://doi.org/10.1136/bmjopen-2016-013960.

18. Gómez I, Prat J, Peremiquel-Trillas P, Claveria Guiu I, Choque E, Oliveira Souto I, Serre Delcor N, et al. A community-based intervention for the detection of Chagas disease in Barcelona, Spain. J Community Health. 2019;44:704-11. https://doi.org/10.1007/s10900-019-00684-z.

19. Meymandi SK, Hernandez S, Forsyth CJ. A community-based screening program for Chagas Disease in the USA. Trends Parasitol. 2017;33:828-31. https://doi.org/10.1016/j.pt.2017.07.003.

20. National Statistics Institute. Foreign population by nationality, communities, sex and year. 2018. https://www.ine.es/jaxi/tabla.do?path=/t20/ e245/p08/11/\&file=03005.px\&type $=$ pcaxis \&L $=1$.

21. Ramos-Sesma V, Navarro M, Llenas-García J, Gil-Anguita C, Torrús-Tendero D, Wikman-Jorgensen $\mathrm{P}$, et al. Asymptomatic strongyloidiasis among latin american migrants in Spain: A community-based approach. Pathogens. 2020;9:1-14. https://doi.org/10.3390/pathogens9060511.

22. Pérez de Ayala Balzola A, Pérez-Molina JA, Navarro Beltrá M, Lopez-Velez R. Enfermedad de Chagas en personas procedentes de Latinoamérica residentes en España. Ministerio de Sanidad y Politica Social. 2009.https:// www.mscbs.gob.es/profesionales/saludPublica/prevPromocion/promo cion/migracion/docs/enfermedadChagas.pdf.

23. Romay-Barja M, Iglesias-Rus L, Boquete T, Benito A, Blasco-Hernández T. Key Chagas disease missing knowledge among at-risk population in Spain affecting diagnosis and treatment. Infect Dis Poverty. 2021;10:55. https://doi.org/10.1186/s40249-021-00841-4.1).

24. Pecoul B, Batista C, Stobbaerts E, Ribeiro I, Vilasanjuan R, Gascon J, et al. The BENEFIT Trial: Where do we go from here? PLOS Negl Trop Dis. 2016;10: e0004343. https://doi.org/10.1371/journal.pntd.0004343.

25. Viotti R, De AlarcónNoya B, Araujo-Jorge T, Grijalva MJ, Guhl F, López $M C$, et al. Towards a paradigm shift in the treatment of chronic chagas disease. Antimicrob Agents Chemother. 2014;58:635-9. https://doi.org/ 10.1128/AAC.01662-13.

26. Newcombe RG. Two-sided confidence intervals for the single proportion: Comparison of seven methods. Stat Med. 1998;17:857-72. https://doi. org/10.1002/(sici)1097-0258(19980430)17:8\%3c857::aid-sim777\%3e3.0. co;2-e.

27. Pane S, Giancola ML, Piselli P, Corpolongo A, Repetto E, Bellagamba R, et al. Serological evaluation for Chagas disease in migrants from Latin American countries resident in Rome, Italy. BMC Infect Dis. 2018;18:212. https://doi.org/10.1186/s12879-018-3118-5. 
28. Jackson Y, Gétaz L, Wolff H, Holst M, Mauris A, Tardin A, et al. Prevalence, clinical staging and risk for blood-borne transmission of chagas disease among latin American migrants in Geneva, Switzerland. PLoS Negl Trop Dis. 2010;4: e592. https://doi.org/10.1371/journal.pntd.0000592.

29. Miranda DLP, Ribeiro G, Lanza FC, Santos FLN, Reis RB, Fraga DBM, et al. Seroprevalence of Trypanosoma cruzi infection among blood donors in the state of Bahia, Brazil. Rev Soc Bras Med Trop. 2019;52: e20190146. https://doi.org/10.1590/0037-8682-0146-2019.

30. Ventura-Garcia L, Roura M, Pell C, Posada E, Gascón J, Aldasoro E, et al. Socio-cultural aspects of Chagas disease: a systematic review of qualitative research. PLoS Negl Trop Dis. 2013;7(9): e2410. https://doi.org/10. 1371/journal.pntd.0002410.

31. Eisenstein M. Disease: poverty and pathogens. Nature. 2016;531(7594):S61-3. https://doi.org/10.1038/531S61a.

32. Mills RM. Chagas disease: epidemiology and barriers to treatment. Am J Med. 2020;133(11):1262-5. https://doi.org/10.1016/j.amjmed.2020.05.022.

33. Salvador F, Treviño B, Chamorro-Tojeiro S, Sánchez-Montalvá A, HerreroMartínez JM, Rodríguez-Guardado A, et al. Imported strongyloidiasis: Data from 1245 cases registered in the +REDIVI Spanish collaborative network (2009-2017). PLoS NegI Trop Dis. 2019;13: e0007399. https://doi. org/10.1371/journal.pntd.0007399.

34. Salvador F, Sulleiro E, Piron M, Sánchez-Montalvá A, Sauleda S, MolinaMorant D, et al. Strongyloides stercoralis infection increases the likelihood to detect Trypanosoma cruzi DNA in peripheral blood in Chagas disease patients. Trop Med Int Health. 2017;22:1436-41. https://doi.org/10.1111/ tmi.12970.

35. Parisi S, Navarro M, du Plessis JD, Shock JP, Apodaca Michel B, Lucuy Espinoza $M$, et al. "We have already heard that the treatment doesn't do anything, so why should we take it?" A mixed method perspective on Chagas disease knowledge, attitudes, prevention, and treatment behaviour in the Bolivian Chaco. PLoS Negl Trop Dis. 2020;14: e0008752. https:// doi.org/10.1371/journal.pntd.0008752.

36. Aldasoro E, Posada E, Requena-Méndez A, Calvo-Cano A, Serret N, Casellas $A$, et al. What to expect and when: Benznidazole toxicity in chronic Chagas' disease treatment. J Antimicrob Chemother. 2018;73(4):1060-7. https://doi.org/10.1093/jac/dkx516.

37. Yun O, Lima MA, Ellman T, Chambi W, Castillo S, Flevaud L, et al. Feasibility, drug safety, and effectiveness of etiological treatment programs for Chagas disease in Honduras, Guatemala, and Bolivia: 10-year experience of Médecins Sans Frontières. PLoS Negl Trop Dis. 2009;3(7): e488. https:// doi.org/10.1371/journal.pntd.0000488.

38. Repetto EC, Zachariah R, Kumar A, Angheben A, Gobbi F, Anselmi M, et al. Neglect of a neglected disease in Italy: the challenge of access-to-care for Chagas disease in Bergamo Area. PLoS Negl Trop Dis. 2015;9: e0004103. https://doi.org/10.1371/journal.pntd.0004103.

39. Fundación MS, Madrid S, Salud EC. Evaluación de la Eficiencia de las Campañas de Cribado Comunitario de la Enfermedad de Chagas en Madrid. Informe de Evaluación de las Campañas 2014-2017; Madrid, España: 2018. https://www.saludentreculturas.es/wp-content/uploads/2019/05/ Cascada-diagnostico-a-tratamiento-EChagas-Final.pdf.

40. Forsyth C, Meymandi S, Moss I, Cone J, Cohen R, Batista C. Proposed multidimensional framework for understanding Chagas disease healthcare barriers in the United States. PLoS Negl Trop Dis. 2019;13: e0007447. https://doi.org/10.1371/journal.pntd.0007447.

41. Bern C, Messenger LA, Whitman JD, Maguire JH. Chagas disease in the United States: a public health approach. Clin Microbiol Rev. 2019;33: e00023. https://doi.org/10.1128/CMR.00023-19.

42. Navarro M, Navaza B, López-Vélez R. Medical assistance is scarcely sought by immigrants and immigrant-travelers in Spain. J Immigr Minor Health. 2013;2013(15):1009-10. https://doi.org/10.1007/s10903-012-9707-2.

43. Iglesias Rodríguez IM, Mizukami S, Manh DH, Thuan TM, Justiniano HA, Miura S, et al. Knowledge, behaviour and attitudes towards Chagas disease among the Bolivian migrant population living in Japan: a crosssectional study. BMJ Open. 2020;10: e032546. https://doi.org/10.1136/ bmjopen-2019-032546.

44. Sanchez DR, Traina MI, Hernandez S, Smer AM, Khamag H, Meymandi SK. Chagas disease awareness among Latin American immigrants living in Los Angeles, California. Am J Trop Med Hyg. 2014;91:915-9. https://doi. org/10.4269/ajtmh.14-0305.

45. Imaz-Iglesia I, Miguel LGS, Ayala-Morillas LE, García-Pérez L, GonzálezEnríquez J, Blasco-Hernández T, et al. Economic evaluation of chagas disease screening in Spain. Acta Trop. 2015;148:77-88. https://doi.org/10. 1016/j.actatropica.2015.04.014.

46. Navarro M, Monge-Maíllo B, Flores-Chavez MD, López-Vélez R. Hunting hidden parasites: Trypanosoma cruzi. Lancet. 2017;19(390):724-6. https:// doi.org/10.1016/S0140-6736(17)31536-2.

47. Navarro M, Navaza B, Blasco T, Clavería I, González M. 'Mothers committed to Chagas' disease: taking action here and there', a community health workers' training program performed in Spain. Abstracts of the 9th European Congress on Tropical Medicine and International Health, 6-10 September 2015, Basel Switzerland. Trop Med Int Health. 2015;20(Suppl 1):1-441. https://doi.org/10.1111/tmi.12575.

48. Blasco-Hernández T, García-San Miguel L, Navaza B, Navarro M, Benito A. Knowledge and experiences of Chagas disease in Bolivian women living in Spain: a qualitative study. Glob Health Action. 2016;9:30201. https:// doi.org/10.3402/gha.v9.30201.

49. Requena-Méndez A, Albajar-Viñas P, Angheben A, Chiodini P, Gascón J, Muñoz J. Health policies to control Chagas disease transmission in European countries. PLoS Negl Trop Dis. 2014;8: e3245. https://doi.org/10. 1371/journal.pntd.0003245.

50. Navarro M, Navaza B, Guionnet A, López-Vélez R. Chagas disease in Spain: Need for further public health measures. PLoS Negl Trop Dis. 2012;6: e3245. https://doi.org/10.1371/journal.pntd.0001962.

51. Colombo V, Giacomelli A, Casazza G, Galimberti L, Bonazzetti C, Sabaini F, et al. Trypanosoma cruzi infection in Latin American pregnant women living outside endemic countries and frequency of congenital transmission: a systematic review and meta-analysis. J Travel Med. 2021. https://doi. org/10.1093/jtm/taaa170.

52. Llenas-García J, Wikman-Jorgensen P, Gil-Anguita C, Ramos-Sesma V, Torrús-Tendero D, Martínez-Goñi R, et al. Chagas disease screening in pregnant Latin American women: adherence to a systematic screening protocol in a non-endemic country. PLoS Negl Trop Dis. 2021;15: e0009281. https://doi.org/10.1371/journal.pntd.0009281.

53. Ramos JM, Milla A, Rodríguez JC, López-Chejade P, Flóres M, Rodríguez $J M$, et al. Chagas disease in Latin American pregnant immigrants: experience in a non-endemic country. Arch Gynecol Obstet. 2012;285:919-23. https://doi.org/10.1007/s00404-011-2081-9.

54. Basile L, Jansa JM, Carlier Y, Salamanca DD, Angheben A, Bartoloni A, et al. Chagas disease in European countries: the challenge of a surveillance system. Euro Surveill. 2011;16:19968.

55. Ramos-Rincón JM, Mira-Solves JJ, Ramos-Sesma V, Torrús-Tendero D, Llenas-García J, Navarro M. Healthcare professionals and students' awareness of Chagas disease: design and validation of Chagas level of knowledge scale (ChaLKS). Am J Trop Med Hyg. 2020;103:437-44. https://doi.org/10. 4269/ajtmh.19-0677.

56. Velasco M, Gimeno-Feliu LA, Molina I, Salas-Coronas J, Sola I, MongeMaillo B, et al. Screening for Trypanosoma cruzi infection in immigrants and refugees: systematic review and recommendations from the Spanish Society of Infectious Diseases and Clinical Microbiology. Euro Surveill. 2020;25(8):1900393. https://doi.org/10.2807/1560-7917.ES.2020.25.8. 1900393 . 